\title{
Amorphous Sulfadoxine: A Physical Stability and Crystallization Kinetics Study
}

\author{
Marique Aucamp, ${ }^{1,2}$ Marnus Milne, ${ }^{1}$ and Wilna Liebenberg ${ }^{1}$
}

Received 2 September 2015; accepted 14 October 2015; published online 3 November 2015

\begin{abstract}
Poor aqueous solubility of drugs and the improvement thereof has always been a challenge for the pharmaceutical industry. With this, one of the focuses of the pharmaceutical research scientist involves investigating possible metastable forms of a given drug to be incorporated into solid dosage forms. The rationale being, the improved solubility offered by the metastable solid-state forms of drugs. Solubility remains a major challenge for formulation scientists, especially with antimicrobial agents where the emergence of resistance is directly dependent on the concentration and duration of the parasite exposed to the drug. Sulfadoxine-pyrimethamine combination therapies are still the recommended treatments for uncomplicated Plasmodium falciparum malaria. The aim of this study was to prepare an amorphous form of sulfadoxine and to investigate the stability and recrystallization behavior thereof. The amorphous form was prepared by the well-known quench cooling of the melt. The physico-chemical properties and stability of amorphous sulfadoxine were studied using hot-stage microscopy (HSM), scanning electron microscopy (SEM), x-ray powder diffractometry (XRPD), differential scanning calorimetry (DSC), thermogravimetric analysis (TGA), as well as microcalorimetry. The recrystallization kinetics were studied isothermally by applying the Johnson-Mehl-Avrami model and non-isothermally by applying the Kissinger model. The physical stabilization of the amorphous form was investigated using physical mixtures of amorphous sulfadoxine with polyvinylpyrrolidone-25 (PVP-25). It was proved that sulfadoxine is a good glass former with relative high physical stability; however, water acts as a strong plasticizer for amorphous sulfadoxine, detrimentally affecting the stability during exposure to high moisture conditions.
\end{abstract}

KEY WORDS: amorphous; crystallization kinetics; stability; sulfadoxine.

\section{INTRODUCTION}

The aqueous solubility of drugs is an age-old and everlasting challenge for the pharmaceutical industry. Usually, a poorly soluble drug leads to an array of problems-from the process of product formulation right up to and including patient treatment. As a result, the pharmaceutical industry started to consider the inclusion of amorphous solid-state forms into solid dosage forms. Current products are being revisited and possibilities that would lead to improved performance of poorly soluble drugs are being investigated extensively.

Rendering a drug amorphous is one common method used to improve the aqueous solubility of a drug (1). In turn, improved aqueous solubility could lead to improved absorption and bioavailability (2-4). The advantage of amorphous materials lies within the lack of a clearly defined molecular structure $(5,6)$. Due to the absence of repeating long-distance molecular order, an amorphous material displays higher mo-

\footnotetext{
$\overline{{ }^{1} \text { Centre of Excellence for Pharmaceutical Sciences, Faculty of Health }}$ Sciences, Potchefstroom Campus, North-West University, 2520, Potchefstroom, South Africa.

${ }^{2}$ To whom correspondence should be addressed. (e-mail: marique.aucamp@nwu.ac.za)
}

lecular mobility and greater inter-molecular distances (6). They possess a higher free-energy state compared to the crystalline form of the same drug, a property which can result in improved solubility and dissolution rate of the drug (6). On the other hand, the fact that it exists in a metastable state, brings forth the disadvantage that it can crystallize to a more thermodynamically stable crystalline state (7). This can occur upon exposure to increased temperature and/or moisture (8). From a manufacturing point of view, this would be disadvantageous and needs to be prevented.

Sulfadoxine is a long-acting sulfonamide antibacterial agent. Sulfonamides are structural analogues and competitive antagonists of p-aminobenzoic acid. Furthermore, they are competitive inhibitors of dihydropteroate synthase, the bacterial enzyme responsible for the incorporation of $\mathrm{p}$ aminobenzoic acid in the synthesis of folic acid. Artemisininbased combination therapies (ACTs), including artesunate plus sulfadoxine-pyrimethamine, are still the recommended treatment for uncomplicated Plasmodium falciparum malaria today (9). In literature, one can find numerous reports of poor in vitro/in vivo dissolution profiles of the sulfadoxine/ pyrimethamine combination products (10-14). Although these studies report on the poor dissolution of sulfadoxine, none clarified or provided a reason for such results. Taking the aforementioned as well as the high morbidity and mortality rates due to malaria into account $(15,16)$, one cannot argue 
that concern should be raised regarding the unsolved problem of poor solubility and dissolution of sulfadoxine.

Currently, no evidence can be found of different solidstate forms in which sulfadoxine can exist and up to this point in time, no amorphous form of sulfadoxine has been reported. The objective of this study was to investigate the possibility of preparing an amorphous solid-state form of sulfadoxine and furthermore to investigate possible stability problems associated with the amorphous form of this anti-malarial drug.

\section{MATERIALS AND METHODS}

Crystalline sulfadoxine was obtained from DB Fine Chemicals (Johannesburg, South Africa), with a potency of 99.2\%. High-performance liquid chromatography (HPLC) grade acetonitrile was purchased from ACE Chemicals (Johannesburg, South Africa), glacial acetic acid, triethylamine, and sodium hydroxide was of analytical grade and was purchased from Merck (South Africa). The polymer (polyvinylpyrrolidone-25) was obtained from DB Fine Chemicals (Johannesburg, South Africa). Water used throughout this study was ultra-pure grade with a resistivity of $18.2 \mathrm{M} \Omega \mathrm{cm}^{-1}$.

\section{Preparation of Amorphous Sulfadoxine}

Amorphous sulfadoxine was prepared by heating a small portion (approximately $500 \mathrm{mg}$ ) of the crystalline form to approximately $198^{\circ} \mathrm{C}$, subsequently quenching it to room temperature on a cool surface. The amorphous habit was confirmed by x-ray powder diffraction (XRPD), differential scanning calorimetry (DSC), and visually through hot-stage microscopy (HSM). Directly after preparation, the purity of the amorphous sulfadoxine sample was confirmed by means of HPLC analysis. HPLC potency analysis indicated that potency of the amorphous sulfadoxine was within the range of $99 \% \pm 1 \%$.

\section{Preparation of Physical Mixtures}

Physical mixtures of amorphous sulfadoxine combined with polyvinylpyrrolidone (PVP-25) were investigated thermally. The mixtures were prepared through mixing amorphous sulfadoxine with PVP-25 using a mortar and pestle. For a homogenous physical mixture, mixing was done for $2 \mathrm{~min}$. The mixtures were prepared in $\% w / w$ concentration and in ratios of $1: 1,1: 2$, and 1:4 (drug/polymer).

\section{Differential Scanning Calorimetry}

A Shimadzu (Kyoto, Japan) DSC-60 instrument was used to record the DSC thermograms. Samples (3-5 mg) were accurately weighed and sealed in aluminum crimp cells. The samples were heated from 25 to $250^{\circ} \mathrm{C}$ with a heating rate of $10^{\circ} \mathrm{C} / \mathrm{min}$ and a nitrogen gas purge of $35 \mathrm{~mL} / \mathrm{min}$. The onset temperatures of the thermal events are reported and the glass transition temperatures $\left(T_{\mathrm{g}}\right)$ were determined from heating scans. For non-isothermal recrystallization studies of amorphous sulfadoxine, approximately $5 \mathrm{mg}$ of the amorphous form was accurately weighed and sealed into aluminum crimp cells. For the samples to which crystalline sulfadoxine was added as seeds, approximately $4 \mathrm{mg}$ of neat amorphous sulfadoxine and $1 \mathrm{mg}$ of crystalline sulfadoxine were weighed into aluminum crimp cells. The same nitrogen gas purge was used as mentioned above. Heating rates of 2, 5, 7, 10, 15, and $20^{\circ} \mathrm{C} / \mathrm{min}$ were used $(n=3)$. For the resulting Kissinger, plots the peak temperatures for the recrystallization of amorphous sulfadoxine was used.

\section{Thermogravimetric Analysis}

A Shimadzu (Kyoto, Japan) thermogravimetric analysis (TGA)-60 instrument was used to determine the percentage weight loss (\%) of the sulfadoxine solid-state forms during heating. Samples (3-5 mg) were accurately weighed into open aluminum crucibles. The samples were heated from $25^{\circ} \mathrm{C}$ to $250^{\circ} \mathrm{C}$ with a heating rate of $10^{\circ} \mathrm{C} / \mathrm{min}$ and a nitrogen gas purge of $35 \mathrm{~mL} / \mathrm{min}$.

\section{Hot-Stage Microscopy}

A small amount of sample was placed on the center of a glass microscope slide and viewed under the microscope. The presence or absence of amorphous material was evaluated by the observance of birefringence, under cross polarized light. HSM analysis was performed with a Nikon Eclipse E4000 microscope, fitted with a Nikon DS-Fi1 camera (Nikon, Japan) and a Linkam THMS600 heating stage equipped with a T95 LinkPad temperature controller (Surrey, England). During heating experiments, a heating rate of $5^{\circ} \mathrm{C} / \mathrm{min}$ was used.

\section{Scanning Electron Microscopy}

Scanning electron microscopy (SEM) images of the purchased crystalline sulfadoxine and the quench cooled amorphous form were also obtained in order to observe possible morphological differences between the samples. For SEM analyses, samples were coated with a layer of gold/palladium using an Eiko engineering ion coater IB-2 (Eiko Engineering, Ibaraki, Japan), and were subsequently imaged using a fieldemission environmental FEI Corporation, Quanta 200ESEM (Hillsboro, Oregon, USA).

\section{X-Ray Powder Diffraction}

Powder x-ray diffraction measurements were performed to confirm the crystalline or amorphous nature of the solidstate forms under investigation. A PANalytical (Almelo, Netherlands) Empyrean x-ray diffractometer with a PIXcel3D detector was used to record XRPD patterns at ambient temperature. Samples were evenly distributed on a zero background sample holder. The measurement conditions for all scans were set as follows: target, $\mathrm{Cu}$; voltage, $40 \mathrm{kV}$; current, $40 \mathrm{~mA}$; divergence slit, $2 \mathrm{~mm}$; anti-scatter slit, $0.6 \mathrm{~mm}$; detector slit, $0.2 \mathrm{~mm}$; scanning speed, $2 \% \mathrm{~min}$ (step size, $0.02^{\circ}$; step time, $1.0 \mathrm{~s})$.

\section{Isothermal Microcalorimetry}

A 2277 Thermal Activity Monitor (TAMIII) (TA Instruments, USA) equipped with an oil bath with a stability of $\pm 100 \mu \mathrm{K}$ over $24 \mathrm{~h}$ was used during isothermal 
recrystallization kinetic studies. The temperature of the calorimeters was maintained at $35,45,55$, or $65^{\circ} \mathrm{C}$. For each analysis, approximately $50 \mathrm{mg}$ of amorphous sulfadoxine was accurately weighed into a 4-mL glass ampoule. For samples in which case crystalline sulfadoxine was added as seeds, approximately $2 \mathrm{mg}$ of crystalline sulfadoxine was added to each glass ampoule. The ampoules were tightly sealed with an aluminum crimp cap. The samples were lowered into the equilibration position of the TAMIII, and the samples were left to equilibrate for $15 \mathrm{~min}$; subsequently, the samples were lowered into the measuring position, an additional $45 \mathrm{~min}$ were allowed for the calorimetric output signal to be considered correct. The experiments were conducted until a heat flow baseline with a drift of $<100 \mathrm{nW}$ was obtained for $12 \mathrm{~h}$. After such a baseline was obtained, the samples were considered to be fully crystallized. The resulting heat flow versus time plots were analyzed using TAMIII Lab Assistant Software V1.3.0.153 (TA Instruments, USA). Integration of the obtained power (heat flow)-time curves, allowed the determination of the heat output of the recrystallization process. From a heat flow versus heat output plot and an iterative procedure applied by the software the rate constant and enthalpy change were then calculated for the recrystallization process.

\section{Vapor Sorption Analysis}

The moisture sorption analyses were performed utilizing a VTI-SA vapor sorption analyzer (TA Instruments, New Castle, Delaware, USA). The microbalance was calibrated prior to each vapor sorption run with a 100-mg standard weight. The microbalance was set to zero prior to weighing of the sample into the stainless steel sample container. The sample was carefully placed into the sample holder and care was taken to evenly distribute the sample. The percentage relative humidity (\% RH)/temperature program was set using TA Instruments Isotherm software. The \% RH ramp was set from $5 \%$ to $95 \%$ $\mathrm{RH}$, followed by a decrease in \% RH from $95 \%$ to $5 \%$. The last absorption phase was set to also ramp from $5 \%$ to $95 \% \mathrm{RH}$. The temperature was set at a constant $25^{\circ} \mathrm{C}$ throughout the \% RH ramp. The program criteria were set to $0.0001 \%$ weight change or 2-min stability of weight gained or lost before the program would continue to the next set parameter.

\section{High-Performance Liquid Chromatography}

HPLC analysis was done utilizing a Shimadzu (Kyoto, Japan) UFLC chromatographic system. The system consisted of a SIL-20AC auto-sampler fitted with a sample temperature controller, a UV/VIS Photodiode Array detector (SPDM20A) and a LC-20AD solvent delivery module. The mobile phase consisted of glacial acetic acid, triethylamine, and water (10:0.5:800, $v / v / v)$. This solution was diluted to $1000 \mathrm{~mL}$, and the $\mathrm{pH}$ was adjusted to 4.2 , with dilute sodium hydroxide. Eight hundred milliliters of this solution was added to $200 \mathrm{~mL}$ acetonitrile. The mobile phase was filtered and degassed prior to use. A Luna C18 $(150 \times 3.9 \mathrm{~mm})$ column was used with a flow rate set to $2.0 \mathrm{~mL} / \mathrm{min}$ and a wavelength of $227 \mathrm{~nm}(17,18)$.

\section{RESULTS AND DISCUSSION}

Up to this point in time, no comprehensive description of the solid-state characteristics of sulfadoxine is available in literature. Also, no mention towards other solid-state forms in which sulfadoxine may exist can be found with literature searches. The molecular structure of sulfadoxine is illustrated in Fig. 1. It consists of low-level branched carbon skeletons, lacks molecular symmetry, and consists of one benzene ring. According to a model utilized by Mahlin et al. (19) in a study to predict the glass forming ability of 16 novel compounds, these structural features of sulfadoxine should grant the drug a fairly high glass forming ability (19). Furthermore, sulfadoxine has four rotatable bonds along the $\mathrm{C}-\mathrm{S}, \mathrm{C}-\mathrm{NH}$, and the two non-equivalent $\mathrm{C}-\mathrm{O}-\mathrm{CH}$ bonds. According to Mahlin et al. (19), this would decrease the likelihood of sulfadoxine being in the proper orientation to undergo nucleation or to be incorporated in an ordered crystalline lattice, resulting in an increased glass forming ability (19). During preliminary studies, it was proved that sulfadoxine can be prepared in an amorphous solid-state form through the well-known, quench cooling of the melt, method. However, the fact that a drug can be classified as a good glass former does not imply that the drug will show good "glass stability."

\section{Glass Forming Ability and Characterization of Amorphous Sulfadoxine}

Figure 2 depicts the thermal analyses of both crystalline and amorphous sulfadoxine. For the commercially obtained sulfadoxine; only one single melting endotherm was observed at approximately $196.76^{\circ} \mathrm{C}\left(\Delta \mathrm{H}_{\mathrm{m}}=-122.08 \mathrm{~J} / \mathrm{g}\right)$. The thermal analysis obtained for amorphous sulfadoxine exhibited a typical DSC thermogram of an amorphous solid-state form of a drug. The glass transition $\left(T_{\mathrm{g}}\right)$ was observed at $\cong 45.71^{\circ} \mathrm{C}$ $\left( \pm 0.52^{\circ} \mathrm{C}\right)$, followed by a thermally induced recrystallization of sulfadoxine at $92.82^{\circ} \mathrm{C}\left(\left(\Delta \mathrm{H}_{\mathrm{c}}=67.67 \mathrm{~J} / \mathrm{g}\right)\right.$. Subsequently, the recrystallized product melted at approximately $196.58^{\circ} \mathrm{C}$. It should be noted that the scan rate used to obtain these results was $10^{\circ} \mathrm{C} / \mathrm{min}$. Therefore, this indicates that amorphous sulfadoxine recrystallized to the stable crystalline form upon heating above the $T_{\mathrm{g}}$. The XRPD diffractograms of both

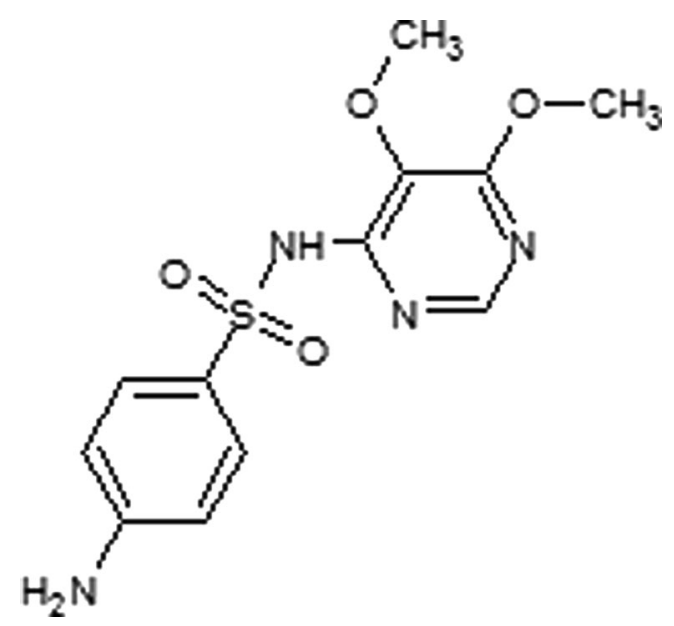

Fig. 1. The chemical structure of crystalline sulfadoxine (11) 


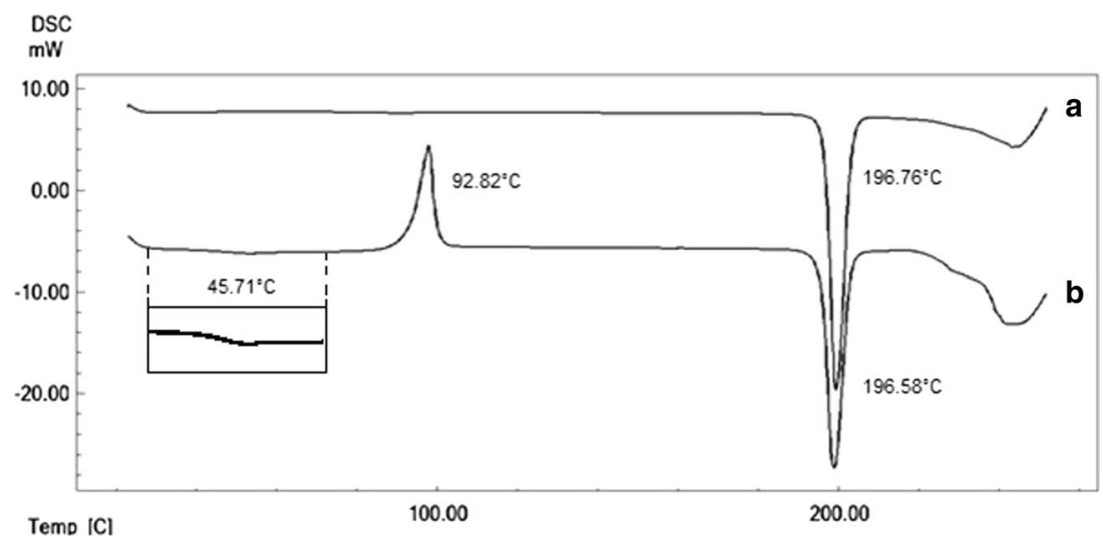

Temo IC

Fig. 2. Overlay of DSC thermograms of $a$ commercially obtained crystalline sulfadoxine and $b$ amorphous sulfadoxine prepared through quench cooling of the melt, with a zoomed inset depicting the glass transition temperature $\left(T_{\mathrm{g}}\right)$

crystalline and amorphous sulfadoxine are depicted in Fig. 3. The absence of diffraction peaks obtained for amorphous sulfadoxine (Fig. 3b) confirms the true amorphous habit thereof.

SEM images further confirmed the amorphous habit of sulfadoxine and were in good agreement with the thermal and crystallography results obtained. Figure $4 \mathrm{a}$, b exhibits the plate-like morphology of sulfadoxine. The smooth glassy surface of amorphous sulfadoxine is depicted in Fig. 4c, d

In order to accurately describe the solid-state properties of any amorphous form of a drug, it is important to investigate parameters which would provide information on the physical stability thereof $(20,21)$. The activation energy $\left(\Delta H^{*}\right)$ of the structural relaxation of amorphous sulfadoxine was determined from the glass transition temperature $\left(T_{\mathrm{g}}\right)$ at different heating rates $(\beta)$ (Table I). It is a well-known fact that the glass transition temperature of an amorphous solid-state form is dependent on the heating or cooling rate $(\beta)$ used during thermal analyses (5,22-24). Therefore, it should be well noted that $T_{\mathrm{g}}$ will shift when higher heating or cooling rates are being used. For this, Eq. 1 applies:

$$
\frac{d \ln |\beta|}{d 1 / T_{\mathrm{g}}}=-\frac{\Delta H^{*}}{R}
$$

Figure 5 depicts the plot of $\ln (\boldsymbol{\beta})$ versus $1000 / \mathrm{T}_{g}$. From the slope of this plot, activation energy $\left(E_{\mathrm{a}}\right)$ of $144.13 \mathrm{~kJ} / \mathrm{mol}$ was calculated. Another meaningful parameter to report in terms of an amorphous form of a drug is the fragility index. This characteristic indicates the increase in the rate of structural relaxation as a "glassy" form of a drug approaches and passes through the glass transition region. The fragility index can be defined as the slope of a $\log _{10} \tau(T)$ versus $T_{\mathrm{g}} / T$ plot;

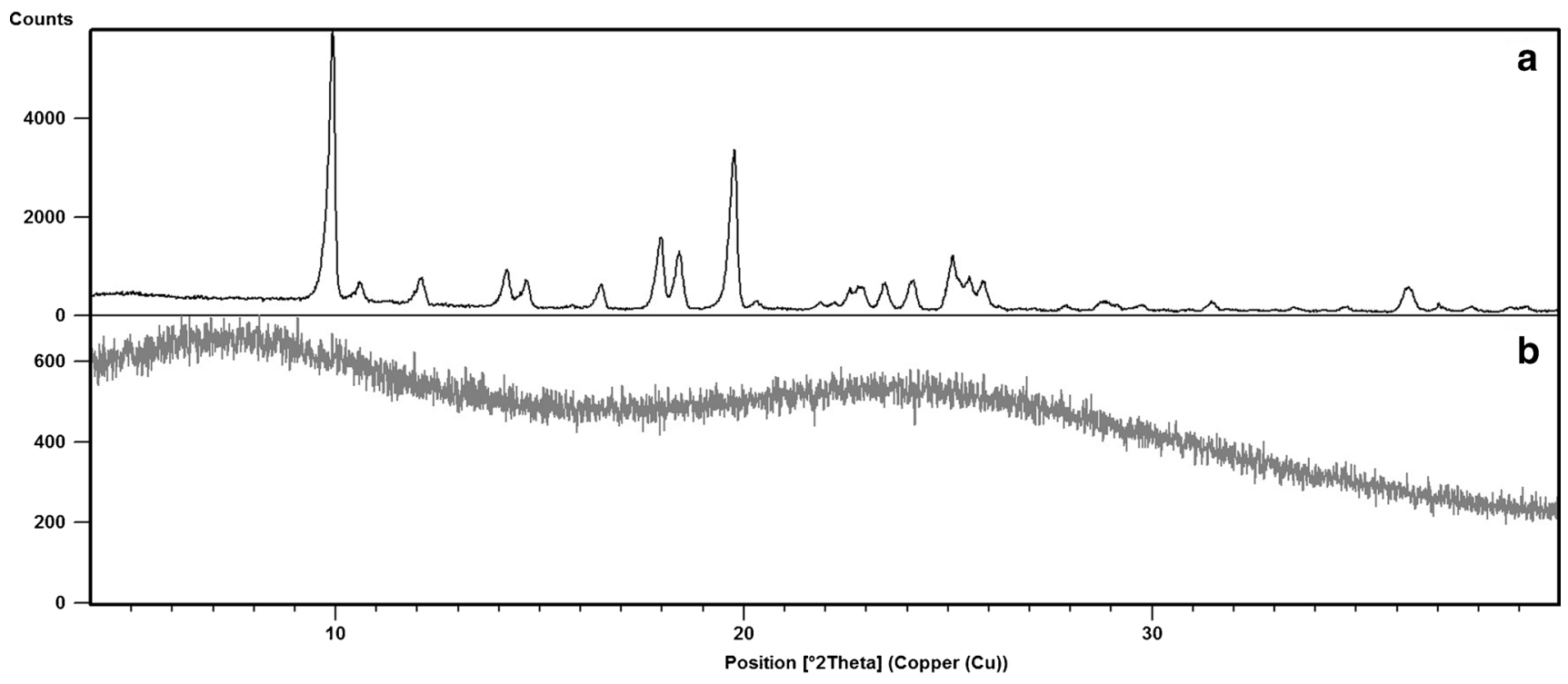

Fig. 3. Overlay of XRPD patterns obtained for $a$ commercially obtained crystalline sulfadoxine and $b$ amorphous sulfadoxine prepared through quench cooling of the melt 

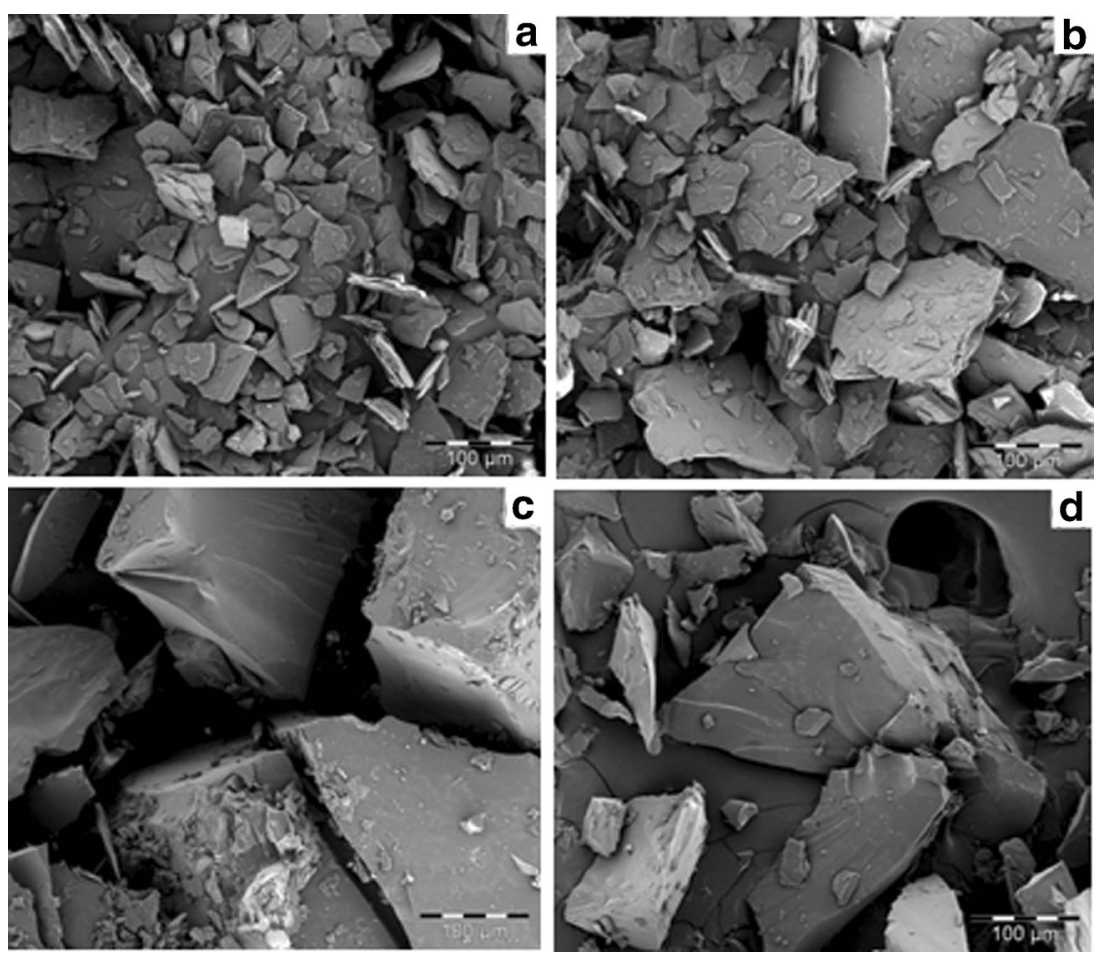

Fig. 4. SEM micrographs of commercially obtained sulfadoxine (a, b) and amorphous sulfadoxine prepared through quench cooling of the melt $(\mathbf{c}, \mathbf{d})$

where $T=T_{\mathrm{g} .}$. From the "Angell plot" for many material types, it was deduced that $\tau$ (structural relaxation time) slows down to $100 \mathrm{~s}$ at $T_{\mathrm{g}}(5,25,26)$. From this, Eq. 2 defines the fragility index $(m)$ as follow:

$m=\left[\frac{d \log 10 \tau(T)}{d\left(\frac{T_{\mathrm{g}}}{T}\right)}\right]$

The fragility of an amorphous system is a dimensionless parameter and actually describes the molecular kinetics which is dependent on the temperature of such a system (26). Equation 2 can also be expressed in terms of temperature dependence and therefore during this study the fragility index $(m)$ of amorphous sulfadoxine was calculated by applying Eq. 3, where the calculated apparent activation energy $\left(E_{a}\right)$ was incorporated into Eq. 2:

$m=\frac{1}{2.303}\left[\frac{E_{\mathrm{a}}\left(T_{\mathrm{g}}\right)}{R T_{\mathrm{g}}}\right]$

Furthermore, it was assumed that the viscosity at $T_{g}$ is $10^{12} / \mathrm{Pa} / \mathrm{s}$ and $\eta_{0}$ is $10^{-5} / \mathrm{Pa} / \mathrm{s}$; this allows for the calculation of the strength parameter $(D)$ by applying Eq. 4 :

$D=\frac{666}{m-17}$

Where 17 is the order of magnitude in the viscosity change from the $T_{\mathrm{g}}$ to $\eta_{0}$. A parameter that closely correlates with the strength parameter is $T_{0}$ which is denoted as the temperature of zero mobility. This temperature is important in pharmaceutical amorphous solid-state forms due to the fact that it can act as a guide of storage temperature which would ensure maximum stability of the amorphous form of a drug. The correlation between $D$ and $T_{0}$ can be expressed in the approximate form of Eq. 5 (5):

$\frac{T_{\mathrm{g}}}{T_{0}}=\frac{1+D}{39.1}$

In literature, it is well described that strong amorphous systems will exhibit a value of $m<40$ while a fragile system will show a value of $m>75$ (5). In the case of the strength parameter $(D)$, typical values between 3 and 7 will indicate a fragile amorphous form, while $D=30$ to $\infty$ is indicative of a strong amorphous form (26). Considering this, it can be concluded that sulfadoxine forms a strong amorphous form (Table II). A low fragility index is considered to be indicative of lower free energy; therefore, a higher physical stability is probable for a strong amorphous system. The glass forming ability of

Table I. Glass Transition Temperatures $\left(T_{g}\right)$ Obtained Through Different Heating Rates $(\beta)$

\begin{tabular}{lc}
\hline Heating rates $\left({ }^{\circ} \mathrm{C} / \mathrm{min}\right)$ & $T_{g}\left({ }^{\circ} \mathrm{C}\right)$ \\
\hline 5.00 & 43.46 \\
7.00 & 47.17 \\
10.00 & 48.84 \\
15.00 & 50.08 \\
20.00 & 51.89 \\
\hline
\end{tabular}




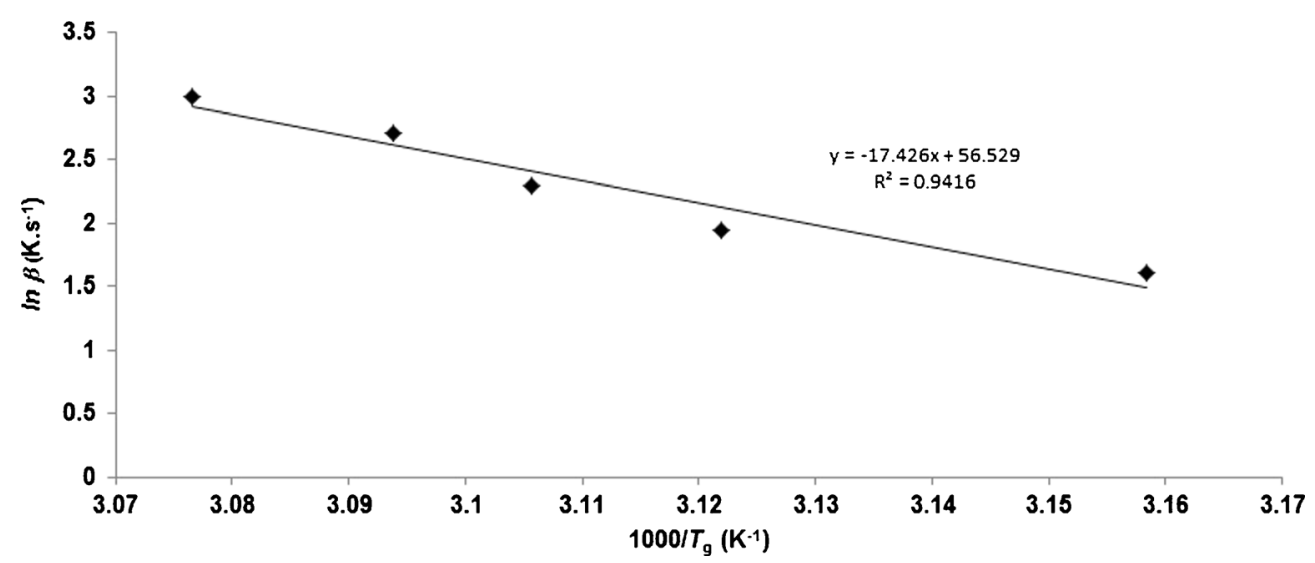

Fig. 5. An Arrhenius plot for the glass transition $\left(T_{\mathrm{g}}\right)$ of amorphous sulfadoxine

sulfadoxine was further investigated by applying the reduced glass transition $\left(T_{\mathrm{rg}}\right)$ method. For this method, Eq. 6 was used, where $T_{\mathrm{g}}$ is the glass transition temperature $(\mathrm{K})$ and $T_{\mathrm{m}}$ is the melting temperature $(\mathrm{K})$ :

$T_{\mathrm{rg}}=\frac{T_{\mathrm{g}}}{T_{\mathrm{m}}}$

The closer the value of $T_{\mathrm{rg}}$ is to 1 , the higher is the glass forming ability of the drug. The calculated value of 0.68 further proved the good glass forming ability of sulfadoxine. This correlating well with the structural features of sulfadoxine and the "prediction" that sulfadoxine would be a good glass former. However, a major drawback that should be kept in mind is the notably low temperature of zero mobility. From this, it can be concluded that amorphous sulfadoxine will have to be stored at least below $\cong 25^{\circ} \mathrm{C}$ in an effort to counter a temperature-dependent transformation of this metastable form to the stable crystalline form of sulfadoxine during mere storage of the bulk material.

It is a well-known fact that the amorphous solid-state form of a drug is a metastable form. As discussed previously, these metastable solid-state forms exist in a higher freeenergy state. Such a higher energy state results in the advantages of improved aqueous solubility and higher dissolution rates. However, the inherent instability of amorphous forms due to the meta-stability of the solid-state should always be

Table II. Physico-Chemical Properties Calculated for Amorphous Sulfadoxine

\begin{tabular}{ll}
\hline $\begin{array}{l}\text { Physico-chemical property of amorphous } \\
\text { sulfadoxine }\end{array}$ & $\begin{array}{l}\text { Calculated } \\
\text { values }\end{array}$ \\
\hline Fragility index $(m)$ & 7.53 \\
Strength parameter $(D)$ & 70.31 \\
Reduced glass transition index $\left(T_{\mathrm{rg}}\right)$ & 0.68 \\
Temperature of zero mobility $\left(T_{0}\right)\left({ }^{\circ} \mathrm{C}\right)$ & 25.06 \\
\hline
\end{tabular}

considered as a disadvantage and should therefore be investigated extensively.

\section{Temperature-Dependent Recrystallization of Amorphous Sulfadoxine}

\section{Non-Isothermal Recrystallization Kinetics}

From the thermal analysis of amorphous sulfadoxine, it can be deduced that the crystallization process is a thermally activated process. The recrystallization kinetics of amorphous sulfadoxine were determined non-isothermally and isothermally. By applying Kissinger's analysis, the activation energy required to obtain recrystallization of amorphous sulfadoxine was determined. It should be noted that the Kissinger model is based on first-order kinetics and therefore, nucleation and crystal growth are not taken into account. This was done by measuring the crystallization temperature from various heating rates $(\beta)$ (Table III). From the obtained thermal analyses, the peak crystallization temperature was used $\left(T_{\mathrm{p}}\right)$. Figure 6 depicts plots of $\ln \left(\beta / T_{\mathrm{p}}{ }^{2}\right)$ versus $1 / T_{\mathrm{p}}$ obtained from DSC analyses of amorphous sulfadoxine without the presence of seeds and with crystalline sulfadoxine seeds present. The slope of the Kissinger plot is $-E_{\mathrm{a}} / R$. The nonisothermal activation energy for amorphous sulfadoxine without the presence of seed crystals was determined to be $173.77 \mathrm{~kJ} / \mathrm{mol}( \pm 28.70)$. The same thermal analysis was done on sulfadoxine amorphous solid-state form but with seed crystals present. The activation energy was determined to be $144.51 \mathrm{~kJ} / \mathrm{mol}( \pm 13.08)$.
Table III. Peak Crystallization Temperatures $\left(T_{p}\right)$ of Amorphous Sulfadoxine Obtained During Different Heating Rates $(\beta)$

\begin{tabular}{ll}
\hline Heating rate $\left({ }^{\circ} \mathrm{C} / \mathrm{min}\right)$ & Peak crystallization temperatures $\left({ }^{\circ} \mathrm{C}\right)$ \\
\hline 5.00 & 94.32 \\
7.00 & 95.16 \\
10.00 & 98.00 \\
15.00 & 100.93 \\
20.00 & 102.93 \\
\hline
\end{tabular}




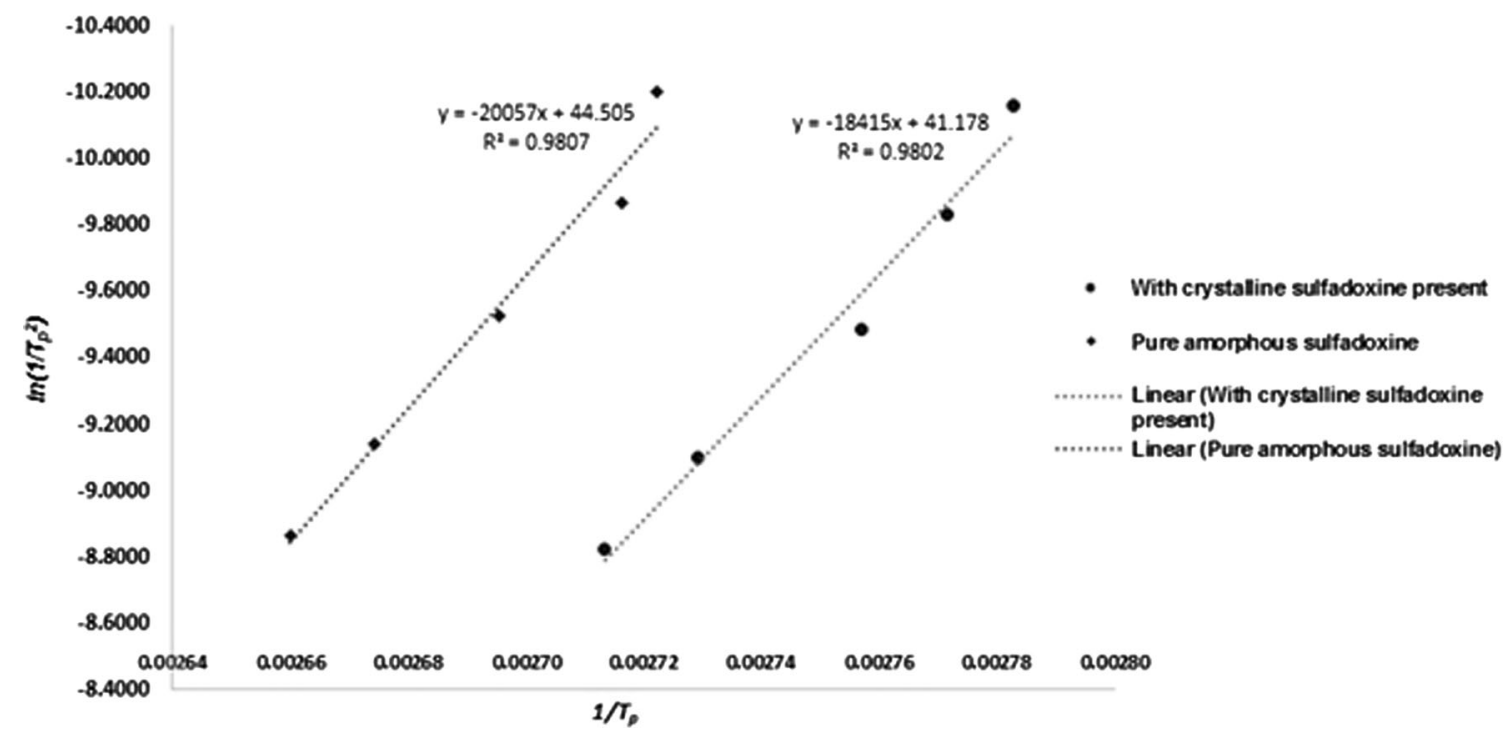

Fig. 6. A Kissinger plot of the non-isothermal crystallization of amorphous sulfadoxine

\section{Isothermal Recrystallization Kinetics}

The recrystallization kinetics of amorphous sulfadoxine was further investigated by the application of the JohnsonMehl-Avrami (JMA) model. This model is viewed to be a suitable model for studying the recrystallization of an amorphous form of a drug due to the fact that it takes into account that the amorphous solid-state coexists with the stable crystalline state during the phase transformation. The JMA model describes the degree of recrystallization as a function of time and can be quantified by applying Eq. 7:

$\alpha=1-e^{-\left[\left(k t-t_{0}\right)\right] n}$

Where $\alpha$ is the fraction of crystalline drug at the temperature of storage time $t, t_{0}$ is the induction time, $k$ is the apparent temperature-dependent rate constant $\left(\right.$ time $\left.^{-1}\right)$, and $n$ is the temperature-independent Avrami exponent (26,27). The Avrami exponent depends on the mechanism of nucleation and growth as well as the number of dimensions $(m)$ in which the growth of the crystals occur $(28,29)$. By assigning an appropriate reaction order, Eq. 7 can be linearized so that Eq. 8 is obtained:

$[-\ln (1-\alpha)]^{1 / n}=k\left(t-t_{0}\right)$

The various nucleation mechanisms are well described in literature $(30,31)$. From hot-stage microscopy (HSM) observations as well as the DSC data, it was clear that the nucleation and crystal growth rate of amorphous sulfadoxine is only a function of temperature. HSM images (Fig. 7b) showed that nucleation sites are formed at temperatures $\cong 49^{\circ} \mathrm{C}-55^{\circ} \mathrm{C}$, from these nucleation sites crystals start to growth with an increase in temperature (Fig. 7c, d). Considering this, three general mechanisms of nucleation would apply, namely: (1) continuous nucleation-nuclei continue to form and grow throughout the transformation process with a first-order time dependence,
(2) fixed number of nuclei-a fixed number of nucleation sites exists and growth proceeds from these preexisting sites, these nuclei will appear at one time with zero-order time dependence, and (3) site-saturated nucleation-which is considered as a combination of mechanisms (1) and (2); in this scenario, all nuclei is present at the onset of the isothermal process, no additional nuclei will form during the transformation but the absolute number of nuclei present is dependent on the temperature (31). Furthermore, crystal growth dimensions $(m)$ is either 1 (unidimensional), 2 (bidimensional), or 3 (tridimensional). Therefore, the reaction order (Avrami exponent) $(n)$, is equal to $m+1$, if nucleation is continuous or equal to $m$ if nucleation is instantaneous (mechanisms (2) or (3) (31). From HSM data (Fig. 7), it was determined that amorphous sulfadoxine recrystallize in a tridimensional manner (spherulitic) and therefore the reaction order was determined to 4 .

Arrhenius plots of the crystallization rate constants (Fig. 8) determined through isothermal microcalorimetry resulted in calculated activation energies of $171.68 \mathrm{~kJ} / \mathrm{mol}$ (without crystalline seeds being present) and $137.07 \mathrm{~kJ} / \mathrm{mol}$ (seeds being present). This showed to be in good correlation with the activation energies calculated through non-isothermal determinations.

\section{Moisture-Induced Recrystallization of Sulfadoxine}

As discussed previously, moisture can also affect the stability of amorphous solid-state forms of drugs. The stability of amorphous sulfadoxine during exposure to moisture was investigated by means of vapor sorption analyses. In comparison with the crystalline form of a drug, an amorphous form can absorb relatively large quantities of water vapor due to greater void space or surface area. Due to the plasticizing effect of sorbed water, the glass transition temperature $\left(T_{\mathrm{g}}\right)$ can be lowered quite significantly. Furthermore, when an amorphous to crystalline phase transition occurs, the water sorption capacity of the drug will decrease significantly. This will result in an overall weight loss due to the fact that excess water 

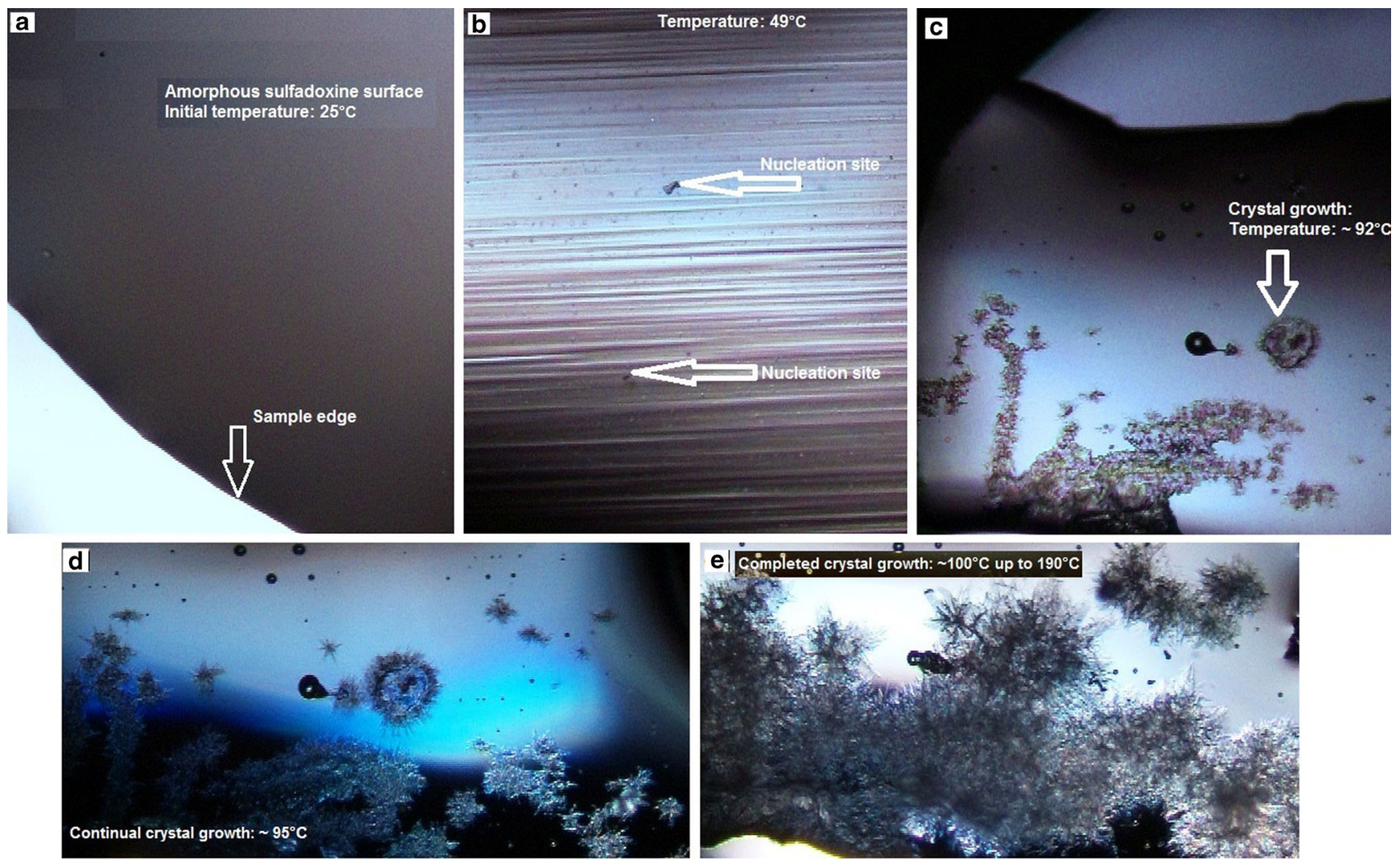

Fig. 7. Photomicrographs obtained during HSM analysis of amorphous sulfadoxine. a Sulfadoxine amorphous form at ambient temperature prior to heating. b Sulfadoxine amorphous form during the heating process at approximately $49^{\circ} \mathrm{C}$, the individual nucleation sites became visible. c Crystal growth from the nucleation sites at a temperature of approximately $92^{\circ} \mathrm{C}$. d Continuous crystal growth can be visually observed from the nucleation sites $\left(95^{\circ} \mathrm{C}\right)$. e Completed crystal growth from the nucleation sites in a tridimensional manner is visible

becomes desorbed during the crystallization process. The specific relative humidity at which crystallization (weight loss) occurs is denoted as $\mathrm{RH}_{\mathrm{c}}(32)$. The moisture sorption analysis of amorphous sulfadoxine showed the critical relative humidity to be $25 \% \mathrm{RH}$ (Fig. 9). This is suspected due to the higher energy state in which amorphous sulfadoxine exists. It is clear that exposure of amorphous sulfadoxine to high moisture environments should be avoided. Due to the instability of amorphous sulfadoxine during exposure to high humidity environments, it was not possible to accurately determine the solubility and dissolution behavior thereof.

\section{Stabilization of Amorphous Sulfadoxine Through Physical Mixtures}

During the last decade or so, the focus moved from preparing neat amorphous forms of drugs to the preparation of amorphous solid dispersions. The advantage of this strategy

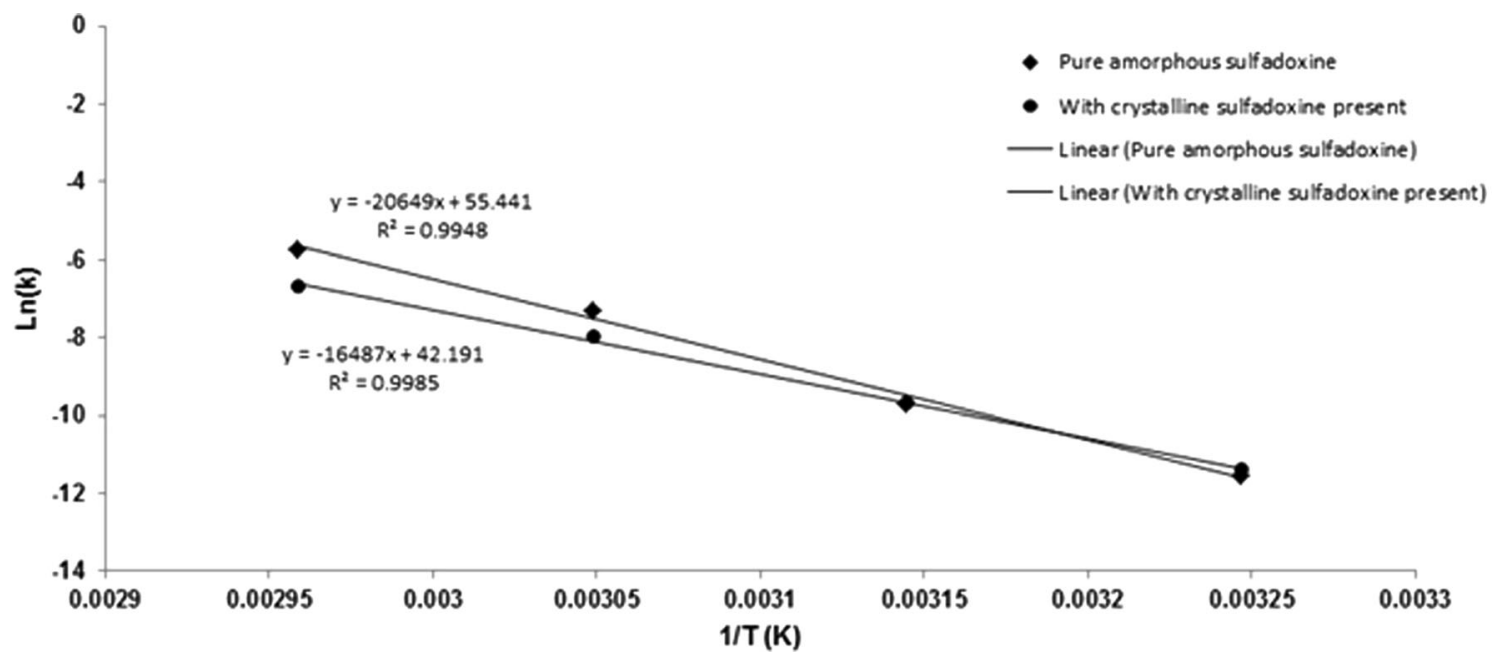

Fig. 8. The Arrhenius plot of the JMA model rate constants determined through isothermal microcalorimetry 


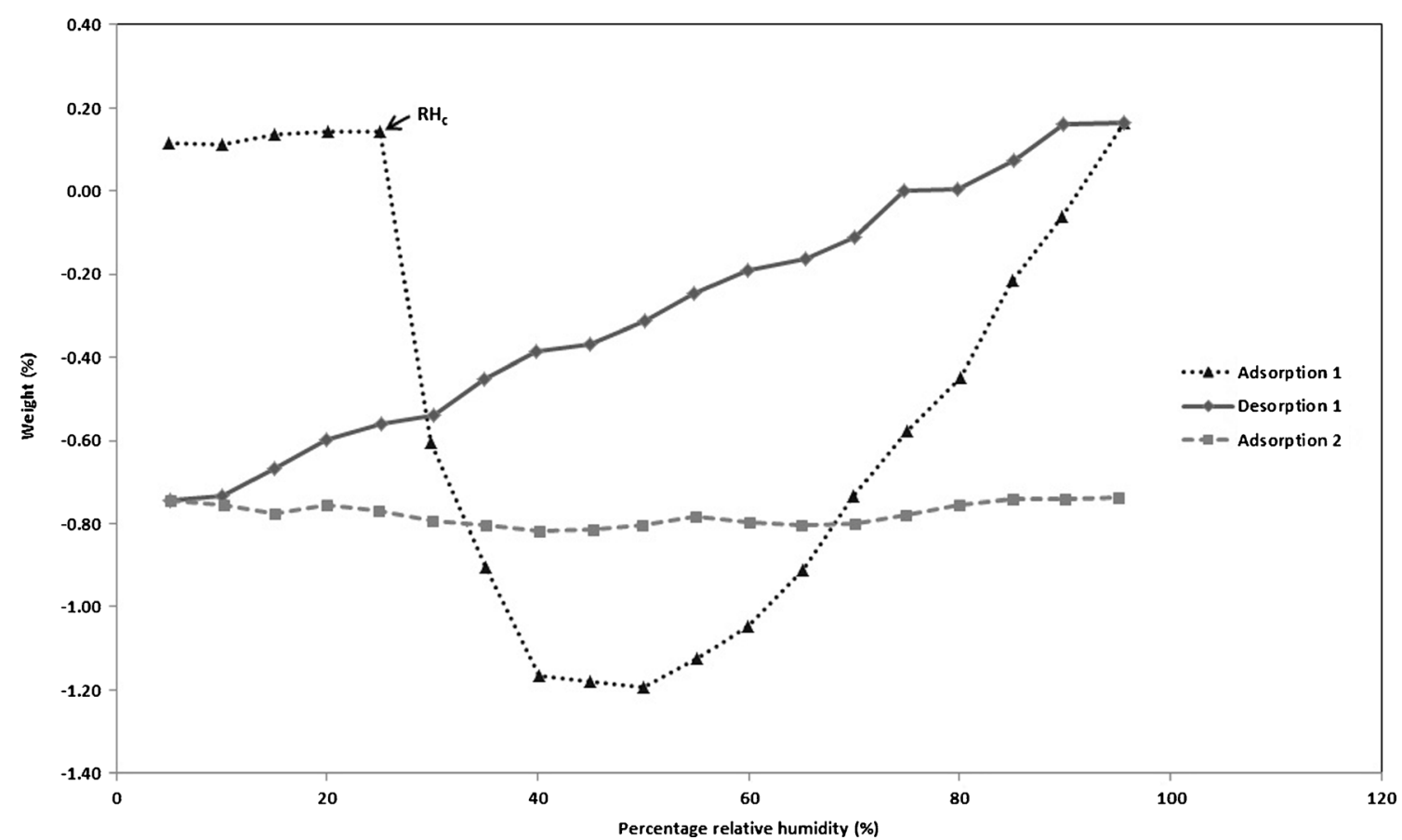

Fig. 9. Moisture sorption isotherms obtained for amorphous sulfadoxine. The isotherms were obtained at $25^{\circ} \mathrm{C}$ with humidity variation of $5 \%-95 \% \mathrm{RH}$

is that an amorphous solid dispersion retains all the advantages of pure amorphous forms of drugs but with better physical stability. Figure 10 depicts the influence that physical mixtures of amorphous sulfadoxine with PVP-25 have on the stability of the amorphous drug.
From Fig. 10, it is apparent that even a physical mixture can result in improved physical stability of amorphous sulfadoxine. A ratio of 1:4 (drug/polymer) showed that the thermally induced recrystallization of amorphous sulfadoxine is being inhibited. The purpose of this study was not to

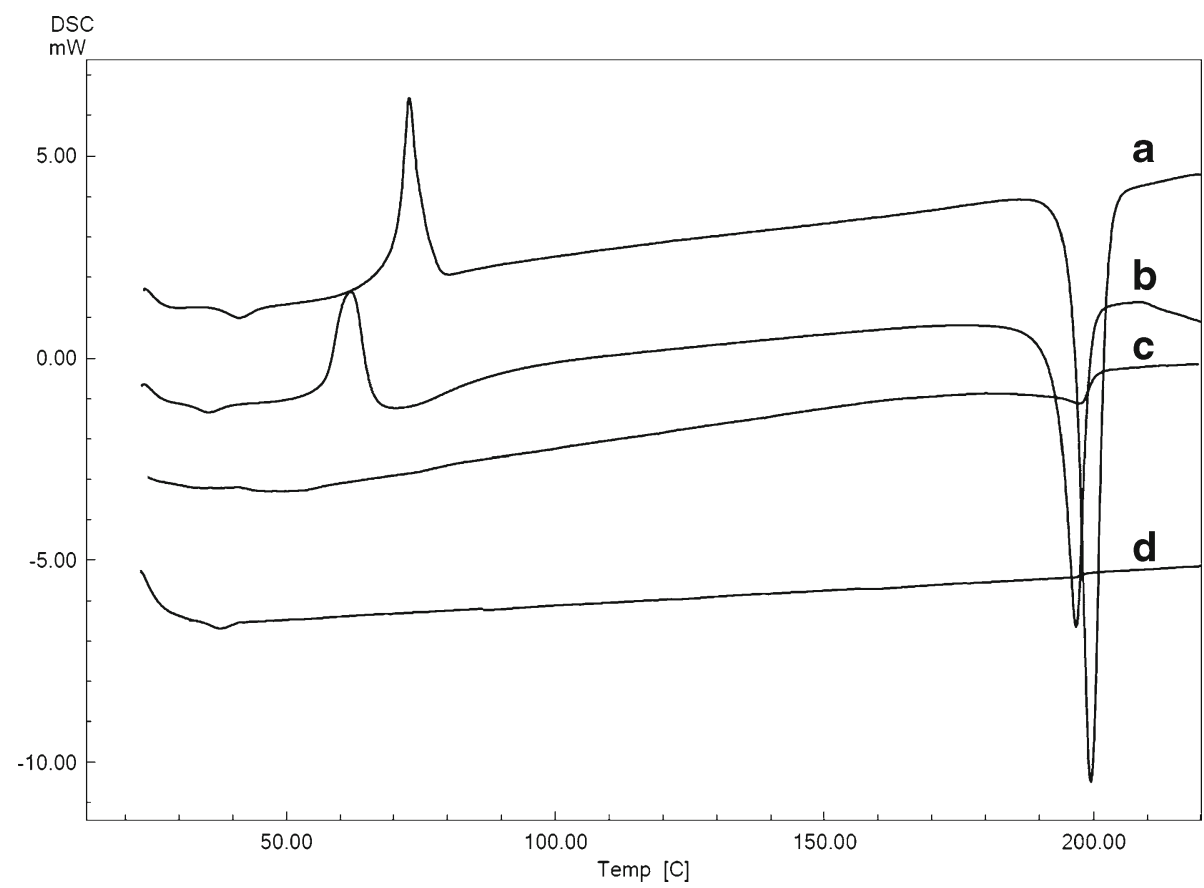

Fig. 10. DSC thermograms obtained during the thermal analysis of physical mixtures of amorphous sulfadoxine with PVP-25. a Neat amorphous sulfadoxine. b Drug/polymer (1:1). c Drug/polymer (1:2). d Drug/polymer (1:4) 
prepare an amorphous solid dispersion of sulfadoxine, but to investigate the influence of polymer/drug physical mixtures on the stability of amorphous sulfadoxine. Future investigations into amorphous sulfadoxine prepared as an amorphous solid dispersion will be considered advantageous.

\section{CONCLUSION}

During this study, an amorphous form of sulfadoxine was successfully prepared by quench cooling of the crystalline solid. The amorphous habit was confirmed with $\mathrm{x}$-ray powder diffraction, through thermal studies and visually through HSM and SEM analyses. It was also shown that sulfadoxine has a good glass forming ability, and that the sulfadoxine glass can be classified as a strong glass. In contrast to literature's dictation that good glass forming ability and strong strength parameters infer good stability, this research heightens the fact that it is not always the case. The critical storage conditions of the amorphous solid-state form (below $25^{\circ} \mathrm{C}$ and $25 \% \mathrm{RH}$ ) needs to be strongly adhered to, in order to prevent temperature- and moisture-dependent transformation to the stable crystalline form. Recrystallization kinetic studies showed that the nucleation and crystal growth rate is temperature dependent and that the presence of crystal seeds significantly decreases the amount of activation energy that is necessary for the recrystallization process to start. Considering the aforementioned, pharmaceutical industries will need to ensure amorphous sulfadoxine without any crystal seeds are used during manufacturing and maintained until after patient consumption. The study further proved that a drug/polymer physical mixture of 1:4 inhibited the thermally induced recrystallization of amorphous sulfadoxine. This, together with the good glass forming ability of sulfadoxine, makes this longacting sulphonamide an ideal candidate for an amorphous solid dispersion.

\section{REFERENCES}

1. Hancock BC, Zografi G. Characteristics and significance of the amorphous state in pharmaceutical systems. J Pharm Sci. 1997;86:1-12.

2. Yellela SRK. Pharmaceutical technologies for enhancing oral bioavailability of poorly soluble drugs. J Bioequiv Availab. 2010;2:28-36.

3. Sharma D, Soni M, Kumar S, Gupta GD. Solubility enhancement-eminent role in poorly soluble drugs. Res J Pharm Technol. 2009;2:220-4.

4. Kumar A, Sahoo SK, Padhee K, Kochar PS, Sathapathy A, Pathak N. Review on solubility enhancement techniques for hydrophobic drugs. Int J Pharm Biol Sci. 2011;3:001-7.

5. Yu L. Amorphous pharmaceutical solids: preparation, characterization and stabilization. Adv Deliv Rev. 2001;48:27-42.

6. Cui Y. A material science perspective of pharmaceutical solids. Int J Pharm. 2007;339(1-2):3-18.

7. Hancock BC, Parks M. What is the true solubility advantage for amorphous pharmaceuticals? Pharm Res. 2000;17:397-404.

8. Baird JA, van Eerdenbrugh B, Taylor LS. A classification system to assess the crystallization tendency of organic molecules from undercooled melts. J Pharm Sci. 2010;99:3787-806.

9. Guidelines for the treatment of malaria. Second Edition. WHO. 2010. http://whqlibdoc.who.int/publications/2010/ 9789241547925_eng.pdf Date accessed: 5 Oct 2015.

10. Schultz LJ, Steketee RW, Macheso A, Kazembe P, Chitsulo L, Wirima JJ. The efficacy of antimalarial regimens containing sulfadoxine-pyrimethamine and / or chloroquine in preventing peripheral and placental Plasmodium falciparum infection among pregnant women in Malawi. Am J Trop Med Hyg. 1994;51:51522 .

11. Amin A, Kokwaro GO. The quality of sulphadoxinepyrimethamine and amodiaquine products in the Kenyan retail sector. J Clin Pharm Ther. 2005;30:559-65.

12. Amin A, Kokwaro GO. Antimalarial drug quality in Africa. J Clin Pharm Ther. 2007;32:429-40.

13. Odeniyi MA, Olajire Adegoke A, Adereti RB, Odeku OA, Itiola OA. Comparative analysis of eight brands of sulfadoxine pyrimethamine tablets. Trop J Pharm Res. 2003;2(1):161-7.

14. Minzi OMS, Moshi MJ, Hipolite D, Massele AY, Tomson G, Ericsson. Evaluation of the quality of amodiaquine and sulfadoxine/pyrimethamine tablets sold by private wholesale pharmacies in Dar Es Salaam Tanzania. J Clin Pharm Ther. 2003;28:117-22.

15. WHO. World malaria report 2015. http://www.who.int/malaria/ publications/world_malaria_report_2014/report/en/ (accessed June 20, 2015).

16. Murray CJL, Rosenfeld LC, Lim SS. Global malaria mortality between 1980 and 2010: a systematic analysis. Lancet. 2012;379:413-31.

17. International Pharmacopoeia 4th edition (2014). http:// apps.who.int/phint/en/p/docf/ Accessed 15 Aug 2015.

18. British Pharmacopoeia (2015). Accessed 14 May 2015. http:// www.pharmacopoeia.co.uk.nwulib.nwu.ac.za/bp2014/ixbin/ bp.cgi.

19. Mahlin D, Ponnambalam S, Höckerfelt MH, Bergström CA. Toward in silico prediction of glass-forming ability from molecular structure alone: a screening tool in early drug development. Mol Pharm. 2011;8(2):498-506.

20. Kaushal AM, Bansal KA. Thermodynamic behavior of glassy state of structurally related compounds. Eur J Pharm Biopharm. 2008;69:1067-76.

21. Ramos JJM, Taveira-marques R, Diogo HP. Estimation of the fragility index of indomethacin by DSC using the heating and cooling rate dependency of the glass transition. J Pharm Sci. 2003;93(6):1503-7.

22. Moynihan CT, Easteal AJ, Wilder J, Tucker J. Dependence of the glass transition temperature on heating and cooling rate. J Phys Chem. 1974;78(26):2673-7.

23. Aucamp ME, Liebenberg W, Strydom SJ, van Tonder EC, de Villiers MM. Physicochemical properties of amorphous roxithromycin prepared by quench cooling of the melt or desolvation of a chloroform solvate. AAPS Pharm Sci Technol. 2012;13(2):467-76.

24. Angell CA. Why $C_{1}=16-17$ in the WLF equation is physical-and the fragility of polymers. Polymer. 1997;38(26):6261-6.

25. Lu Q, Zografi G. Properties of citric acid at the glass transition. J Pharm Sci. 1997;86(12):1374-8.

26. Maffezzoli A, Kenny JM, Torre L. On the physical dimensions of the Avrami constant. Thermochim Acta. 1995;269/270:185-90.

27. Ruitenberg G, Woldt E, Petford-Long AK. Comparing the Johnson-Mehl-Avrami-Kolmogorov equations for isothermal and linear heating conditions. Thermochim Acta. 2001;378:97105.

28. Smith GW. A method for determination of Avrami parameters directly from isothermal calorimetry data. Thermochim Acta. 1997;291:59-64.

29. Schmitt EA, Law D, Zhang GGZ. Nucleation and crystallization kinetics of hydrated amorphous lactose above the glass transition temperature. J Pharm Sci. 1998;88(3):291-6.

30. Sinclair W, Leane M, Clarke G, Dennis G, Dennis A, Tobyn $\mathrm{M}$, et al. Physical stability and recrystallization kinetics of amorphous ibipinabant drug product by Fourier transform Raman spectroscopy. J Pharm Sci. 2011;100(11):4687-99.

31. Wolt E. The relationship between isothermal and nonisothermal description of Johnson-Mehl-Avrami-Kolmogorov kinetics. J Phys Chem Solids. 1992;53:521-7.

32. Burnett DJ, Thielmann F, Booth J. Determining the critical relative humidity for moisture-induced phase transitions. Int J Pharm. 2004;287(1-2):123-33. 